\title{
INFLUENCIAS EN LA FILOSOFÍA MORAL CARTESIANA: CONCEPTOS GENERALES
}

\author{
INFLUENCES IN CARTESIAN MORAL \\ PHILOSOPHY: GENERAL CONCEPTS
}

\author{
Diana Solano Villareal \\ Universidad Nacional de Costa Rica
}

Recibido: 23 de enero, $2015 \bullet$ Aceptado: 15 de mayo, 2015

\begin{abstract}
Resumen: En este artículo sondeo las influencias en la filosofía moral cartesiana, las cuales remiten principalmente a la antigüedad. Aristóteles, Epicuro y los estoicos son las fuentes más profundizadas. Por otra parte, los conceptos generales que considero más importantes para desarrollar posteriormente la tesis central de este trabajo (a saber, el papel de la filosofía moral cartesiana en las formas de dominio hacia el ser humano en la modernidad) son revisadas en este apartado. Los conceptos de virtud, hábito, voluntad, generosidad, beatitud, razón, sabiduría, filosofía y el soberano bien son analizados. También realizo una pequeña referencia sobre la influencia scotiana, de la mano del genio Etienne Gilson. Todo en busca de indicios que permitan probar que la moral cartesiana pudo haber dado lugar a una relación de control de unos seres humanos sobre otros.
\end{abstract}

Palabras clave: Descartes, filosofía moral, control, humanos

Abstract: In this first article, we explore the influences on the Cartesian moral philosophy which mainly refer to antiquity. Aristotle, Epicurus and the Stoics are the most in-depth sources. Moreover, the general concepts we consider most important to further develop the central thesis of this work (the role of moral philosophy Cartesian forms of domination towards the human being in modernity), are reviewed in this section. The concepts of virtue, habit, will, generosity, bliss, reason, wisdom, philosophy and the sovereign good, are analyzed. We also make a small reference to Scotus influence of the hand of genius Etienne Gilson. We search for clues that prove that the Cartesian morality can lead to a relationship of control of some human beings over others.

Keywords: Descartes, moral philosophy, control, human 
Ainfi je croy que la vraye Generofité, qui fait qu'un homme s'eftime au plus haut point qu'il fe peut legitimement eftimer, confifte feulement, partie en ce qu'il connoift qu'il n'y a rien qui véritablement luy appartiene que cette libre dilpolition de fes volontez,ny pourquoy il doive eilre loué ou blafmé, finon pource qu'il en ufe bien ou mal ; \& partie en ce qu'il fent en foy mefme une ferme $\&$ confiante refolution d'en bien ufer, c'eft à dire de ne manquer jamais devolonté, pour entreprendre \& exécuter toutes les chofes qu'il jugera eftre les meilleures. Ce qui eft fuivre parfaitement la vertu1

Art. 153

Les passions de l'ame

Descartes

\section{Introducción}

Renato Descartes (1596-1650) ha sido tradicionalmente conocido por estudios epistemológicos, metafísicos, científicos e incluso matemáticos, pero muy poco por sus incursiones en la filosofía moral. Resulta un hecho interesante que durante mucho tiempo se pensara que Descartes no exploró los ámbitos morales dado su carácter metódico, sin embargo este autor generó también reflexiones evidentemente morales.

Por otra parte, la filosofía moral cartesiana es ampliamente conocida como una cuestión problemática. El imperativo cartesiano de encontrar un camino firme y seguro que guíe el comportamiento humano riñe directamente con una moral contingente y en elaboración sostenida por Descartes en el Discours de la méthode (1637), Les passions de l'âme (1649) y en su correspondencia moral. El tema del presente trabajo versa fundamentalmente sobre la filosofía moral cartesiana, no se pregunta si existe o no. Asumo la filosofía moral cartesiana como real y existente, quizás no tan sistematizada como otros temas, pero existente al fin. La temática de esta tesis explora el tema del control en la obra cartesiana, más no el control sobre la naturaleza, sino hacia el ser humano.

1 Así, creo que la verdadera generosidad, que hace que un hombre se estime en él más alto grado que puede legítimamente estimarse, consiste, en parte, en que conoce que esta libre disposición de sus voluntades es lo único que le pertenece y que solamente por el uso bueno o malo que haga de esa libre disposición puede ser alabado o censurado, y en parte en que siente en s mismo una firme y constante resolución de hacerlo bueno, es decir, de no carecer nunca de voluntad para emprender y ejecutar todas las cosas que juzgue mejores; lo cual es seguir perfectamente la virtud. 
Las razones que me llevaron a realizar esta investigación- entregada en tres partes, de las cuales este es el primer artículo— se centran en el control hacia el ser humano en la obra cartesiana que hunde sus raíces en las teorías poscoloniales, específicamente en la teoría de la modernidad bipolar del Dr. Bernal Herrera, estudiada en uno de los cursos del Posgrado en Filosofía de la Universidad de Costa Rica, y en la que encontré una fascinante nueva lectura del Discours de la méthode.

El Discours de la methode, obra de agradable lectura y de aparentes planteamientos fáciles, revela toda una nueva propuesta moral con alcances epistemológicos. A su vez, llamaron mi atención otros títulos de su obra en los que consideré que podría encontrar más evidencias de la hipótesis que lentamente se estaba formando. Entre estos títulos destacaron, Les passions de l'âme y los intercambios epistolares de Descartes con la princesa Isabel de Bohemia y con varios amigos suyos, entre ellos Mersenne. No obstante, la correspondencia con la princesa Isabel de Bohemia fue especialmente estimulante. Las temáticas que se tratan en las cartas entre el filósofo de Touraine y la princesa palatina son absolutamente fascinantes. Las virtudes, la vida feliz, las pasiones en el alma y la templanza del espíritu son solo algunos de los tópicos desarrollados.

Ahora bien, ¿cómo se relaciona la teoría de la modernidad bipolar con los escritos morales, antropológicos y epistemológicos de Descartes? Pienso que en los planteamientos morales y epistemológicos cartesianos se esconde una no intencionada teoría del control del ser humano por el ser humano, toda vez que el autor del Discours de la méthode dejó muy claro en la segunda parte de la obra recién mencionada que el método que allí se expone no es para todos y, por ende, no todos están calificados para tener acceso a la verdad.

Por otra parte, la teoría del doctor Herrera señala que dos de los estandartes de la modernidad, la libertad y el conocimiento, nunca han sido ofrecidos a todos los seres humanos de forma igualitaria, y que incluso en la metrópoli su despacho ha sido parcial. En este sentido, en parte de la obra cartesiana se puede encontrar evidencia del enunciado de una libertad y un conocimiento que, en este caso, no es para todos. De esta forma surgió mi interés por la filosofía moral y la epistemología de Descartes. 
Para llevar a cabo esta investigación he utilizado los siguientes textos: Regulae ad Directionem Ingenii (1628), El Discours de la methode (1637), Meditatione de prima philosophia (1641), Principia philosophae (1644) y Les passions de l'ame, también conocido como El tratado de las pasiones (1649). Además, he hecho uso de las valiosas cartas sobre temas morales de Descartes con varios interlocutores. Para efectos de este trabajo son fundamentales las relaciones epistolares mantenidas con la princesa Isabel de Bohemia y la reina Cristina de Suecia. Esta nutrida correspondencia se encuentra recopilada en los tomos del uno al cinco de Oeurres de Descartes (Adam y Tannery, 1897). ${ }^{2}$

Esta disertación es un análisis interpretativo del discurso moral y epistemológico cartesiano, para establecer si la interconexión entre estas ramas de la filosofía, mediante el control de la voluntad, da como resultado una propuesta de control de unos seres humanos hacia otros. Se realiza este trabajo apoyándose en las fuentes mencionadas sin desligar la obra de su conjunto. La disposición metodológica para este trabajo es bibliográfica. Es importante indicar que las fuentes revisadas, es decir, los textos escogidos de Descartes, fueron leídas en sus idiomas originales, es decir, francés y latín. Las traducciones del francés y del latín se incluirán en una nota al pie de página después de cada cita textual.

En este primer documento exploro las influencias en la filosofía moral cartesiana y los conceptos generales que considero más importantes para desarrollar posteriormente la tesis central de este grupo de trabajos. Las influencias revisadas en este apartado remiten principalmente a la antigüedad. Aristóteles, Epicuro y los estoicos son las fuentes más profundizadas. Los conceptos de virtud, hábito, voluntad, generosidad, beatitud, razón, sabiduría, filosofía y el soberano bien son analizados. También realizo una pequeña referencia sobre la influencia scotiana, de la mano del genio Etienne Gilson. Todo en busca de indicios que permitan probar que la moral cartesiana pudo haber dado lugar a alguna relación de control de unos seres humanos sobre otros.

En este grupo de trabajos espero probar la hipótesis que los crea y los impulsa. Ha sido un trabajo muy arduo pero a la vez edificante. Descartes se yergue ante nosotros como un ser humano iluminado, brillante, que creía de verdad en el ser humano como un ser perfectible, que siempre puede ser mejor.

2 Las citas aparecidas en el texto que pertenecen a esta edición en once volúmenes de Adam y Tannery (19641986) quedan consignadas de la siguiente manera: (A.T., volumen, página; línea). 


\section{Generalidades de la filosofía moral cartesiana}

Distinto a otros grandes filósofos, anteriores y posteriores a él, Descartes no escribió obra alguna dedicada expresamente a la filosofía moral. Es más, lo que se conoce de su pensamiento moral se encuentra desperdigado tanto en sus obras destinadas al público como en sus epístolas, pero especialmente en estas últimas, y más específicamente en la correspondencia sostenida con la princesa Isabel de Bohemia y con la reina Cristina de Suecia. La filosofía moral cartesiana se hace un poco más evidente a partir del Discours de la méthode.

Para Descartes la filosofía moral es una ciencia que, al igual que las otras ciencias, encuentra su basamento en la metafísica y por eso mismo en la razón. ${ }^{3}$ Empero, la filosofía moral no es una ciencia como las demás, sino la más sublime y elaborada:

Ainsi toute la Philosophie est comme vn arbre, dont les raicines Font la Metaphysique, le tronc est la Physique, y les branches qui sortent de ce tronc sont toutes les autres sciences, qui se reduisent a trois principales, a scauoir la Medecine, la Mechanique y la Morale, j'entens la plus haute y la plus parfaite Morale, qui, presupposant vne entiere connoissance des autres sciencies, est le dernier degré de la Sagesse (A.T., IX-2, p. 14; 23-31)4.

Según se muestra en la cita anterior, la filosofía moral cartesiana se yergue como la ciencia máxima, la cual está nutrida por una larga tradición ética, y, como se verá más adelante, en especial del estoicismo. Para poder actuar moralmente Descartes tenía como condición necesaria razonar correctamente. El buen razonar depende de los conocimientos y del control

3 La razón como potencia del espíritu es parte de los estudios de la metafísica, en cuanto no puede ser conocida por los sentidos. La razón es «el sentido», es un «algo» que no aparece definido en ninguna parte de la obra del filósofo francés: «Le bon sens est la chose du monde la mieux partagée; car chacunpense en être si bien pourvu que ceux même qui sont les plus difficiles à Contenter en toute autre chose n'ont point coutume d'endésirer plus qu'ils en ont» (El buen sentido es lo que mejor repartido está entre todo el mundo, pues cada cual piensa que posee tan buena provisión de él, que aun los más descontentadizos respecto a cualquier otra cosa, no suelen apetecer más del que ya tienen) (A.T. VI, 1; 18. 2; 1-3). Sens se ha traducido siempre como razón.

4 La totalidad de la Filosofía se asemeja a un árbol, cuyas raíces son la Metafísica, el tronco es la Física y las ramas que brotan de este tronco son todas las otras ciencias que se reducen principalmente a tres: a saber, la Medicina, la Mecánica y la Moral, entiendo por esta la más alta y perfecta Moral, que presuponiendo un completo conocimiento de las otras ciencias, es el último grado de la Sabiduría. 
de las pasiones, pues una mente bien nutrida y disciplinada estará en una mejor posición para tomar buenas decisiones.

Ahora bien, hay que recordar que cuando Descartes hablaba de conocimiento no se refería a cualquier conocimiento, este debía poseer algunas características especiales, por ejemplo, debía ser simplex mentis inspectio (simple inspección de la mente). La simplex mentis inspectio equivale a una intuición (Ferrater, 1963). El evidencialismo cartesiano restringe las opciones del conocimiento necesario para juzgar bien, encontrar ideas claras y distintas y guiar adecuadamente el juicio.

Las situaciones corporales y mentales, como se dice hoy, jugarían un importante papel en el proceso de razonamiento, y por esto Descartes señaló que una filosofía moral completa debía contener un buen conocimiento del organismo humano y sus funciones.

Por otra parte, Descartes abordó los temas morales mayoritariamente en su correspondencia con la reina Cristina de Suecia, su amigo Marin Mersenne y con la princesa Isabel de Bohemia. Esta última, siendo una mujer inteligente y de una excelente formación intelectual, solicitaba repetidamente aclaraciones sobre la relación entre dos sustancias tan distintas como el alma y el cuerpo en el ser humano, por lo cual el filósofo francés escribió el tratado sobre Les passions de l'âme, donde se encuentran varias consideraciones que ahondan en algunos de los argumentos que Descartes había expresado antes.

A lo anterior debe agregarse un importante aspecto de la personalidad de Descartes: su desagrado por las disputas y los altercados públicos, que lo llevó al alejamiento en un lugar apartado para no tomar posición sobre un tema como la moral, que por sus características propias tiende a la polémica y a la controversia. Por esto, el pensamiento moral cartesiano es de características muy diversas, propiamente sistemático solamente en Les Passions de l'âme, y a veces muy personal.

Al respecto, en una carta del 20 de noviembre de 1647, Descartes le dijo a Chanut: «Il est vray que i' ay coûtume de refuser d' écrire mes pensees touchant la Morale»(A.T., V, p. 86; 25-26)5 , y ello por dos razones: la primera, porque es un tema en el cual las personas maliciosas encuentran muy fácilmente pretextos para calumniar; la segunda, porque es potestad de

5 Es cierto que tengo costumbre de reusar a escribir mis pensamientos con respecto a la moralidad. 
los soberanos, o de aquellos a quienes ellos deleguen, llevar a cabo la tarea de regular las costumbres de los demás. ${ }^{6}$

Sin embargo, pese a las situaciones anteriormente mencionadas, en la obra cartesiana se encuentra un gran número de pasajes que contienen reflexiones y afirmaciones de claro alcance moral.

\section{Las influencias sobre la moral cartesiana}

Aun cuando se sabe que Descartes no fue propiamente un filósofo moral, tuvo pensamientos y reflexiones de corte moral ¿En qué o en quién se inspiraron las ideas, los epítomes y los conceptos sobre moral en Descartes? Es importante contestar esta pregunta. Conocer las bases de la filosofía moral cartesiana ayudará a entender cómo la ética de Descartes puede dar pie al control hacia el ser humano por el ser humano. Desde luego espero contestar la pregunta antes planteada de manera superficial, pues no es parte de los objetivos de esta tesis, ni cuento con espacio para realizar una investigación muy detallada de las influencias en la filosofía moral cartesiana, la que sin lugar a dudas es ya de por sí una tarea peligrosa y delicada.?

No obstante, se pueden establecer en Descartes los gérmenes de su pensamiento moral. La veta de pensamiento moral cartesiano más aceptada por los expertos es la de los antiguos escritos paganos. Sobre estos Descartes expresó:

Ce que les Anciens en ont enseigné est si peu de chose, $\&$ pour la plus part si peu croyable, que je ne puis avoir aucune esperance d'approcher de la vérité, qu' en m' éloignant des chemins qu' ils ont suivis (A.T., XI, p. 327; $17-18 /$ p. $328 ; 1-2)^{8}$.

6 A pesar de esta afirmación, en este capítulo busco probar que, si bien Descartes no pretendía regular las costumbres de los otros, existe un planteamiento consciente o quizás más seguramente inconsciente respecto al control que algunas personas con determinadas características morales podrían ejercer sobre otros individuos.

7 La razón por la que considero arriesgado profundizar en el tema de las influencias en el pensamiento moral de Descartes es que casi no mencionó a los filósofos o las escuelas que pudieron ejercer algún influjo en su pensamiento moral. Son excepcionales las menciones a nombres propios como Platón, Aristóteles o Séneca, quien es el filósofo más aludido por Descartes. De hecho, aparece en tres de las cartas enviadas a la princesa Isabel de Bohemia, a saber: las del 21 de julio, 4 de agosto y 18 de agosto de 1645; en la carta del 18 de agosto Descartes trató el libro De beata vita del filósofo latino, así como el pensamiento ético de Epicuro, Zenón y Aristóteles respecto a la naturaleza del bien supremo y de la beatitud (A.T, IV, pp. 275-277). Epicuro es el único al que le reconoció algún acierto en el tema de la beatitud.

8 Lo que los antiguos enseñaron es tan poco, y en su mayor parte tan poco creíble, que no puedo tener ninguna esperanza de aproximarme a la verdad... 
A pesar de lo dicho en el párrafo anterior, Descartes recurrió a los antiguos implícita y explícitamente, con más frecuencia la primera. Las principales fuentes antiguas de las cuales bebió el filósofo francés en cuanto a su filosofía moral son Aristóteles, Epicuro y el estoicismo. Estos autores anteriormente citados aparecen abiertamente nombrados en la carta del 18 de agosto de 1645, dirigida a la princesa Isabel (A.T., IV, p. 275; 24-26).

En una carta del 21 de julio de 1645 el filósofo francés le recomendó a la atribulada princesa Isabel una lectura que le ayudaría a fortalecer su espíritu: «L' vn des ces moyens, qui me semble des plus vtiles est d'examiner ce que les anciens en ont escrit» (A.T., IV, p. 252; 20-21) $)^{9}$. La lectura en cuestión era el libro De beata vita de Séneca, obra sobre la cual volvió en una carta posterior (carta a la princesa Isabel, 4 de agosto de 1645), en la que explicó las razones por las cuales le recomendó el texto antes mencionado y su distancia respecto al pensamiento del filósofo estoico. En esa misma misiva Descartes expresó pensamientos claramente estoicos: «Que de parler des moyens que la Philosophie nous enseigne pour acquérir cete fouueraine félicité, que les ames vulgaires attendent en vain de la fortune, \& que nous ne sçaurions auoir que de nous mesmes» (A.T., IV, p. 252; 15-19) ${ }^{10}$.

En una carta de junio de 1645 el filósofo francés insistió: «Car il n’y a point d'éuenemens si funestes, ny si abfolument mauuais au iugement du peuple, qu' vne personne d' esprit ne les puisse regarder de quelque biais qui fera qu' ils luy paroistront fauorables (A.T., IV, p. 237; 7-10) ${ }^{11}$.

El 6 de octubre de ese mismo año Descartes le reiteró a la princesa Isabel que se debe emplear especial destreza en mirar las cosas por el lado que las hace parecer más ventajosas para nosotros, antes que por el lado en el que resaltan sus defectos (A.T., IV, p. 315; 7-12). En enero de 1646 le indicó que no se debe prestar mayor atención a lo que existe fuera de nosotros y no depende de nuestro libre arbitrio. Lo que conviene es prestar atención a las cosas que sí dependen, por ello: «Là comparaison de celles qui en dépendent, lesquelles nous pouuons tousiours rendre bonnes, lors que nous en sçauons bien vfer il» (A.T., IV, p. 355; 17-19) ${ }^{12}$.

\footnotetext{
9 Uno de estos medios, que creo que es más útil, es examinar lo que los antiguos escribieron.

10 que hablan de manera que la filosofía nos enseña a adquirir esta soberana felicidad, como almas vulgares esperan en vano la fortuna, y que nosotros no sabríamos obtener de nosotros mismos.

11 Porque hay un punto de evento tan fatal, o juicio tan absolutamente malo de la gente, que una persona de espíritu no puede mirar de cualquier manera que hará sus paredes de frente favorables.

12 La comparación con aquello que depende, de lo que todavía podemos reparar cuando sabemos hacer el bien.
} 
Asimismo, la tercera máxima de la morale par provision ('moral por provisión' o 'de provisión') dice que: «Il n'y a rien qui soit entièrement en nostre pouvoir, que nos pensées» (A.T., VI, p. 25; 23-25) ${ }^{13}$. Expresión de obvia influencia estoica. Descartes tomó del estoicismo y otras doctrinas de la antigüedad algunas ideas éticas, incluso recibió mucho influjo del ideal del sabio estoico, aunque por supuesto no se puede afirmar simplemente que la moral cartesiana sea solamente estoica.

Si bien es cierto que en ocasiones el estoicismo está presente en el pensamiento moral cartesiano de manera muy destacada y es fácil de identificar, en otras lo hace de un modo un poco más solapado y prudente. También es indudable que el filósofo francés no se limitó a repetir la moral estoica sin más y que en ocasiones asumió una abierta separación de algunas de las ideas y los juicios estoicos.

Entre las principales diferencias entre el estoicismo y Descartes se puede mencionar la concepción de la felicidad. Para los estoicos la felicidad es la quietud del ánimo derivada de la despreocupación respecto a las cosas que no dependen de nosotros. Además, para el filósofo de Touraine la felicidad se da en la alegría de vivir. Para Descartes la felicidad del sabio está también en la meditación sobre el amor intelectual a Dios.

La felicidad y la independencia de esta de la fortuna y de los acontecimientos externos al individuo son puntos focales en la filosofía moral cartesiana y de suma importancia para los efectos de este trabajo, pues la diferenciación entre quienes logran independizarse de la fortuna para ser felices y quienes no pueden es un punto determinante.

\section{Otras influencias: el epicureísmo y Aristóteles}

Otra importante influencia en la filosofía moral cartesiana es el pensamiento de Epicuro, en especial la Carta a Meneceo y las Máximas capitales. En la epístola del 18 de agosto de 1645 a la princesa Isabel, Descartes deliberaba acerca del soberano bien desde tres filósofos: Epicuro, Zenón y Aristóteles, y solo manifestó estar de acuerdo con Epicuro, a quien, además de nombrar, reconoció su mérito e intercedió por su adecuada interpretación:

13 No hay nada que esté enteramente en nuestro poder, que nuestros pensamientos. 
Enfin Epicure n'a pas eu tort, confiderant en quoy consiste la béatitude, \& quel est le motif, ou la fin a laquelle tendent nos actions, de dire que c'est la volupté en gênerai, c'est a dire le contentement de l'esprit; car, encore que la seule connoissance de noftre deuoir nous pourroit obliger a faire de bonnes actions, cela ne nous feroit toutefois iouir d'aucune beatitude, s' il ne nous en reuenoit aucun plaisir (A.T., IV, p. 276; 20-27) ${ }^{14}$.

El filósofo francés se abocó a corregir las interpretaciones equivocadas respecto a Epicuro. Empero, Descartes no volvió a ocuparse de Epicuro de manera explícita, solamente de manera solapada o indirecta, al igual que ocurre con el estoicismo.

Respecto a la fortuna, el filósofo de Touraine aconsejó no confiarse de ella, tal como le comunicó a Chanut: «Au reste, il semble que la fortune est ialouse de ce que ie n'ay iamais rien voulu attendre d'elle, \& que i' ay tasché de conduire ma vie en telle forte, qu'elle n'eust fur moy aucun pouuoir» (A.T., V, p. 328; 1-4) ${ }^{15}$.

En cuanto a Aristóteles, su influencia sobre el filósofo francés se evidencia en la insistencia de este último en el equilibrio, en el justo medio del Estagirita. En el artículo XLVIII de Les passions de l'âme se ilustra claramente esta noción. Igualmente, en la tercera parte del Discours de la méthode Descartes hizo alusión al equilibrio. El equilibrio es también característico, tal como se verá y se ampliará más adelante, de las almas que tienen control sobre sus pasiones.

En este punto es muy válido preguntarse si con los antiguos se agotan las influencias sobre Descartes, y la respuesta es no. El filósofo francés consiguió crear un sistema de pensamiento alternativo al aprendido en La Fléche, es decir, el de la filosofía aristotélico-tomista, ${ }^{16}$ que siempre encontró insuficiente $^{17}$ y consideró que jamás podría encontrar el camino hacia la verdad.

Empero, a pesar de la reticencia de Descartes a la Escolástica, según los estudios de Étienne Gilson (1952) en realidad nunca se libró realmente de la

14 Y, por último, Epicuro no yerra cuando dice, al examinar en qué consiste la beatitud y cuál es el motivo o la finalidad a que tienden nuestros actos, que es la voluptuosidad en general, es decir, el contento del espíritu, es decir, la alegría mente; porque, aunque el solo conocimiento de nuestro deber nos podría obligar a hacer buenas obras, no nos haría sin embargo disfrutar ninguna bienaventuranza, si no nos regresa ningún placer.

15 Además, parece que la suerte está celosa de esto que no quería esperar jamás nada de ella, y yo que trataré de conducir mi vida en tal fuerza, que ella no tenga ningún poder sobre mí.

16 Ver E., Gilson (1966).

17 Ver E., Gilson (1925). 
Escolástica aprendida en su juventud. Por otra parte, los estudios de Jolivet (1945) han demostrado la presencia del nominalismo en la obra cartesiana. No obstante, este trabajo versa fundamentalmente sobre la filosofía moral cartesiana, por lo que no ahondaré en el tema de la influencia escolástica en la obra de Descartes.

\section{Conceptos generales de la filosofía moral cartesiana}

En este apartado me propongo examinar los conceptos fundamentales de la filosofía moral cartesiana. Empero, esta labor no será sencilla, pues las nociones morales se encuentran fuertemente enlazadas unas con otras, haciendo muy difícil y en ocasiones imposible aislarlas para efectos de análisis.

\section{La virtud, el hábito y la voluntad}

El tema de la virtud en Descartes es un tema que hay que examinar con paciencia, pues es fundamental para entender su pensamiento moral. El concepto de virtud es la base para los otros términos morales. En la carta del 4 agosto dirigida a la princesa Isabel Descartes mencionaba la virtud como uno de los componentes importantes para una vida feliz:

Considerant, apres cela, ce que c'eft quod beatam vitam essiciat, c'eft a dire quelles sont les chofes qui nous peuuent donner ce fouuerain contentement, ie remarque qu'il y en a de deux fortes : a scauoir, de celles qui depedent de nous, comme la vertu \& la sagesse, \& de celles qui n' en dependent point (A.T., IV, p. 264; 14- 19) ${ }^{18}$.

En la siguiente carta, dirigida a la princesa Isabel, Descartes trató de nuevo el tema de la virtud:

C'est pourquoy ie croy pouuoir icy conclure que la beatitude ne consiste qu'au contentement de l' esprit, c'est a dire au contentement en general; car bien qu`il y ait des contentemens qui dependent du cors, \& des autres

18 Considerando después de esto, que es la esencia de la vida feliz, es decir, cuáles son aquellas cosas que podemos dar esta satisfacción soberana, yo señalo que hay dos fuertes: a saber, de aquellas que dependen de nosotros como la virtud y la sabiduría, y de aquellas que no dependen al punto. 
qui n`en dependent point, il n`y en a toutefois aucun que dans l`esprit : mais que, pour auoir vn contentement qui soit solide, il eft besoin de suiure la vertu, c'est a dire d'auoir vne volunté serme $\mathcal{B}$ constante d' executer tout ce que nous iugerons estre le meilleur, \& d' employer toute la forcé de nostre entedement a en bien iuger [el subrayado es mío] (A.T., IV, p. 277; 15-25) ${ }^{19}$.

La virtud es un hábito que depende de dos cosas: un buen juicio, es decir, el conocimiento para juzgar bien y una voluntad firme, o sea, una voluntad controlada al punto de mantener las decisiones tomadas firmes y constantes. Poco más tarde, en la misiva del 1 de setiembre de 1645 dirigida a la princesa Isabel, Descartes volvió sobre la virtud:

Mais affin de sçauoir exactement combien chasque chose peut contribuer a nostre contentement, il faut considerer quelles sont les causes qui le produisent, \& c'est aussy l' vne des principales connoissances qui peuuent seruir a faciliter l' vsage de la vertu; car toutes les actions de nostre ame qui nous acquerent quelque perfection (A.T., IV, p. 283; 23-29) ${ }^{20}$.

Entonces, la virtud tiene que ver no solo con la voluntad y el buen juicio, sino también con el contento y el perfeccionamiento del ser humano: «Y tout nostre contentement ne consiste qu' au tesmoignage interieur que

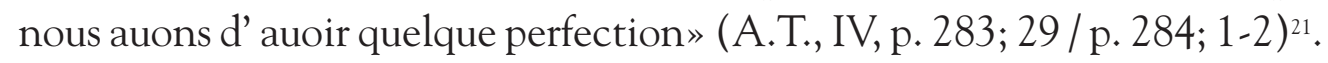

Más tarde, el 15 de setiembre de 1645, Descartes le escribió a la princesa Isabel que para juzgar bien son necesarias dos cosas:

ce me semble, y auoir que deux choses qui soyent requises pour estre tousiours dispofé a bien iuger: l' vne est la connoissance de la verité, \& qu' on acquiesce a cete connoissance, a toutes les fois que l'occasion le requert (A.T. VI, 291;11-16). Ft bien que nous ne puissions auoir des demonstrations certaines de tout, nous

19 Es por eso que creo que puedo concluir que la dicha beatitud no consiste en la alegría del espíritu, es decir del contento en general; así la satisfacción de la que depende de los cuerpos, y otros que dependen al punto, que sin embargo no tienen en el espíritu: pero, para tener una satisfacción que sea sólida, se necesita seguir la virtud, es decir tener una voluntad firme y constante para ejecutar lo que juzgamos mejor, y emplear toda la fuerza de nuestro entendimiento en bien juzgar.

20 Pero con el fin de saber exactamente cómo todo puede contribuir nuestra satisfacción, debemos considerar cuáles son las causas que lo producen, y eso es también uno de los principales conocimientos que se pueden utilizar para facilitar la sabiduría de la virtud; porque todas las acciones de nuestra alma nos acercan a alguna perfección.

21 Y todo nuestro contento no consiste más que en el testimonio interior de tener alguna perfección. 
deuons neanmoins prendre parti, \& embrasser les opinions qui nous paroissent les plus vraysemblables, touchant toutes les choses qui vienent en vfage, affin que, lorsqu'il est question d'agir, nous ne soyons iamais irresolus. Car il n'y a que la

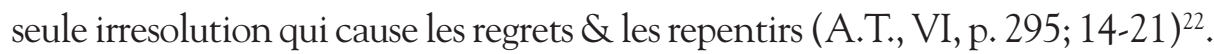

Así las cosas, Descartes señaló que para practicar la virtud, que es un hábito, se debe aplicar disciplina y voluntad:

Au reste, i' ay dit cy dessus qu'outre la connoissance de la verité, l' habitude est aussy requise, pour estre tousiours difposé a bien iuger. Car, d'autant que nous ne pouuons estre continuellement attentifs a mesme chose, quelques claires \& euidentes qu' ayent esté les raisons qui nous ont persuadé cy deuant quelque verité, nous pouuons, par apres, estre de- tournez de la croyre par de fausses apparences, si ce n'est que, par vne longue $\&$ frequent meditation (A.T., VI, p. 295; 22 / p. 296; 12) ${ }^{23}$.

En Les passions de l'âme, en el artículo CLXI, Descartes concibe la virtud de manera similar:

Il convient de noter que ce qui est communément appelé les vertus de l'âme sont des habitudes qui prédisposent à certaines pensées, de sorte que les vertus sont différentes de ces pensées, mais ils peuvent produire et, à l'inverse, être produites par eux (A.T., XI, p. 453; 8-12) ${ }^{24}$.

Sobre el mismo tema de la virtud, en el artículo CXC se reafirma lo anterior: «La Satisfaction, qu'ont tousjours ceux qui suivent constamment

22 me parece que hay dos cosas que se requieren para estar siempre dispuesto a bien juzgar: el uno es el conocimiento de la verdad que nos acerca a este conocimiento, cada vez que la ocasión lo requiere (AT VI, 291; 11-16)... y aunque no podemos tener la demostración cierta de todo, debemos tomar partido, y abrazar las opiniones que nos parecen las más verdaderas, tocando todas las cosas que vienen de la sabiduría con el fin de que, cuando se trata de actuar nunca estemos irresueltos. Porque no solo la indecisión es la que causa los arrepentimientos y los remordimientos.

23 Además, he dicho anteriormente que además del conocimiento de la verdad, también se requiere el hábito, para estar siempre preparado para juzgar bien. Porque, tanto como no podemos estar continuamente atentos a la misma cosa, algunas evidentes y claras que habiendo sido las razones que nos persuadieron hasta ahora algo de verdad, porque podemos a partir de entonces se des-rotar la creencia no por falsas apariencias, si no que por una larga y frecuente meditación

24 Cabe señalar que lo que comúnmente se llama las virtudes del alma son hábitos que predisponen a ciertos pensamientos, por lo que las virtudes son diferentes de esos pensamientos, pero pueden ocurrir y, por el contrario, ser producido por ellos. 
la vertu, est une habitude en leur ame, qui se nomme tranquillité \& repos de conscience» (A.T., XI, p. 471; 14-16) ${ }^{25}$.

Para comprender aún mejor el concepto de virtud en Descartes es preciso observar la epístola dedicatoria de los Principia philosophia. Esta carta de gran complejidad tiene como destinataria «A la Serenísima Princesa Isabel». En esta misiva Descartes realizó una serie de consideraciones en torno a la virtud, amparada solo por las verdades que se puedan respaldar con la experiencia y la razón.

El mencionado texto inicia señalando la diferencia existente «entre les vraies vertus et ceux qui ne sont qu'apparentes».(A.T., IX, p. 2; 21-22) ${ }^{26}$. Las virtudes verdaderas son las que proceden de un exacto conocimiento de la verdad, y las aparentes aquellas que están acompañadas de la ignorancia o del error. Para Descartes hay vicios que pueden confundirse con virtudes. Un ejemplo lo constituye la temeridad. Confundida con una virtud, la temeridad hace que los pródigos reciban más agasajos que los generosos y que adquieran mejor reputación los supersticiosos y los hipócritas que las gentes de bien (A.T., IX, p. 2; 21-22).

Para evitar este tipo de confusiones Descartes quiso precisar en qué consisten propiamente las virtudes:

En ce qui concerne les vraies vertus, tous viennent pas d'une vraie connaissance, mais il ya certains qui sont nés aussi, parfois, imperfection ou erreur, cela se produit lorsque la simplicité est la cause de la bonté, ou lorsque la peur devient dévotion ou de désespoir, de courage (A.T., IX, p. 2; 22) ${ }^{27}$.

A modo de epítome de todo lo anterior, se puede decir que la virtud es la determinación inquebrantable de la persona de obrar lo mejor que se pueda en cada circunstancia de su vida, ayudándose constantemente de los acertados juicios del entendimiento y de los conocimientos que posea. El hábito (alcanzado por la práctica de la virtud) hará que se recuerde fácilmente el conocimiento necesario para juzgar de la mejor forma posible y así obrar correctamente, con lo cual, según Descartes, se estaría siguiendo la virtud y, con ella, viviendo feliz.

25 Satisfacción que tienen siempre los que constantemente siguen la virtud es un hábito en su alma, que se llama la tranquilidad y el reposo de la conciencia.

26 verdaderas virtudes y los que son solo aparentes.

27 En cuanto a las verdaderas virtudes, no todos vienen de un verdadero conocimiento, pero hay algunos que han nacido también a veces la imperfección o error, que ocurre cuando la simplicidad es la causa de la bondad o cuando el miedo se convierte en la devoción y la desesperación, coraje 
El conocimiento necesario para juzgar bien (los juicios son actos de voluntad $)^{28}$ no es necesariamente fruto de una segunda naturaleza, sino también de ideas innatas. El innatismo de Descartes se hace presente en este punto, cuando se nos dice que existen ideas que «non enim unquam fcripfi vel judicavi, mentem indigere ideis innatis, quae fint aliquid diverfum ab ejus facultate cogitandi; fed cùm adverteremquafdam in me efle cogitationes, quae non ab objectis externis, nec à voluntatis meae determinatione procedebant» ${ }^{29}$ (A.T., VIII, p. 2; 358).

De esta manera, esas ideas que preexisten en los seres humanos, con un poco de constancia y una voluntad firme se usarán para crear el hábito. En estas condiciones se vivirá feliz, pues la conciencia nunca nos reprochará que dejamos de hacer lo que creíamos que era lo mejor. Por lo demás, es importante reiterar que tanto el hábito como la virtud exigen siempre una voluntad $^{30}$ firme, en otras palabras, suficiente control de la voluntad.

\section{La generosidad}

La importancia que Descartes le dio a la generosidad es muy grande. La generosidad es una virtud y a la vez una pasión que nos conduce a la sabiduría, que sintetiza todas las virtudes y por ello ocupa un lugar privilegiado en la filosofía moral cartesiana.

En la filosofía moral cartesiana no parece haber problema en que una pasión pueda ser también una virtud. En el artículo CLXI se aprecia esto: «L'âme ne peut produire ces pensées seul, mais souvent pensé un mouvement renforce l'esprit, d'où sont les actions vertueuses, tandis que les passions de l'âme»(A.T., XI, p. 453; 14-17) 31.

28 Ver A.T., VII; pp. 376-377(Notae in programma quoddam) A.T., VIII; p. 117.

29 Descartes señaló en varios de sus escritos (Ej. A.T., VII, pp. 105-106 y p. 189 / A.T., VIII, p. 2, pp. 357-358 y p. 366.) que existen ciertas facultades mentales innatas en los seres humanos, puestas en nosotros por Dios. Estas facultades son la percepción y el asentimiento. En cuanto a las ideas innatas propiamente dichas Descartes indicó que este tipo de ideas (pues el filósofo francés en ningún momento afirmó que todas las ideas sean innatas) se encuentran en los seres humanos desde la etapa fetal (A.T., III, p. 242 / A.T., VII, pp. 356-357).

30 Según el artículo 18 de Les passions de l'âme, hay dos clases de voluntad: unas son las acciones del alma, que se cumplen en el alma misma, como cuando queremos amar a Dios o en general aplicar nuestro pensamiento a algún objeto que no es material. Esta es la voluntad que interesa en este trabajo.

31 El alma no sólo puede producir estos pensamientos, pero a menudo se piensa un movimiento fortalece la mente, que son acciones virtuosas ... 
La generosidad como pasión se transforma, o más bien deriva en virtud estimulando las pasiones primitivas de las que está compuesta, a saber: la admiración, el gozo y el amor, y así adquirir, en consecuencia, la virtud de la generosidad. Meditando con frecuencia sobre el libre arbitrio es como «nous ne pouvons exciter passion en nous-mêmes et par conséquent d'acquérir la vertu de générosité qui, étant comme la clé de toutes les autres vertus»

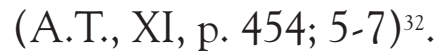

Al final del artículo CLXI Descartes reiteró la importancia de meditar sobre el libre arbitrio y las ventajas que nos da hacer buen uso de él (del libre arbitrio), no solo para alcanzar la generosidad, sino también como un remedio general contra todas las confusiones que ocasionan las pasiones.

A mi parecer, en el artículo CLIII de Les passions de l'âme el filósofo francés definió la generosidad de la manera más clara:

Ainsi je croy que la vraye Generosité, qui fait qu'un homme s'estime au plus haut point qu'il se peut legi timement estimer, consifte seulement, partie en ce qu'il connoift qu'il n'y a rien qui véritablement luy appartiene que cette libre disposition de ses volontez, ny pourquoy il doive estre loué ou blasmé, sinon pource qu'il en use bien ou mal; \& partie en ce qu'il sent en soy mesme une ferme \& constante resolution d'en bien ufer, c'est à dire de ne manquer jamais de volonté,pour entreprendre \& exécuter toutes les choses qu'il jugera estre les meilleures. Ce qui est fuivre parfaitement la vertu (A.T., CLIII, p. $445 ; 26-27$ / p. 446; 1-10) $)^{33}$.

Para entender mejor la definición anterior hay que saber en qué consisten la estima y, su contraparte, el menosprecio. Descartes en el artículo CXLIX señaló que:

Et l'Estime, entant qu'elle est une Passion, est une inclination qu' a l'ame à se representer la valeur de la chose estimée, laquelle inclination est causée

32 No podemos excitar la pasión en nosotros mismos y, por tanto, para adquirir la virtud de la generosidad, de ser la clave de todas las demás virtudes

33 Así que creo que la verdadera generosidad hace que un hombre se siente en lo más alto que pueda legítimamente estimarse solamente consiste, en parte, que él sabe que no hay nada que realmente le aparte de esta libre disposición de su voluntad, ni por qué debe ser alabado o blasfemado, si no por lo que él usa bien o mal; y parte como lo que siente en sí mismo, una constante y firme resolución de buen uso, es decir, que nunca se quede sin voluntad de emprender y ejecutar todas las cosas que considere la mejor. Esto es seguir perfectamente la virtud. 
par un mouvement particulier des esprits, tellement conduits dans le cerveau, qu'ils y fortifient les impressions qui servent à ce sujet (A.T., CXLIX, p. 443; $18-19$ / p. 444; $1-4)^{34}$.

Al contrario, la pasión del menosprecio es una inclinación del alma que tiende a «representer la valeur de la chosée estimée, laquelle inclination est causée par un mouvement particulier des esprits» (Ibídem) ${ }^{35}$. Estas pasiones (la estima y el menosprecio) surgen de la pasión primitiva de la admiración en el artículo CL:

Ainsi ces deux Passions ne sont que des especes d' Admiration. Car lors que nous n' admirons point la grandeur ny la petitesse d'un objet, nous n' en faisons ny plus ny moins d' estat que la raison nous dicte que nous en devons faire; de façon que nous l'estimons ou le mesprisons alors sans passion (A.T., XI, p. 444; 12-17) $)^{36}$.

En el artículo CLI se explica que también podemos considerarnos a nosotros mismos como objetos de estima o desprecio: «Or ces deux Passions se peuvent generalement rapporter à toutes sortes d'objets; mais elles sont principalement remarquables, quand nous les rapportons à nous mesmes, c'est à dire, quand c'est nostre propre merite que nous estimons ou mesprisons»

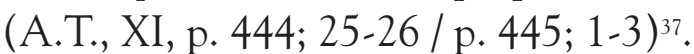

Para Descartes (artículo CLII) hay una sola cosa que puede explicar que nos estimemos o nos menospreciemos:

Je tascheray icy d'en dire mon opinion. Le ne remarque en nous qu'une seule chose, qui nous puisse donner juste raison de nous estimer, à sçavoir l'usage de nostre libre arbitre, \& l'empire que nous avons sur nos volontez. Car il n’y a que les seules actions qui dépendent de ce libre arbitre, pour lesquelles

34 Y la estima, en tanto que es una pasión, es una inclinación que el alma tiene para representar el valor de la cosa estimada, aquella inclinación es causada por un movimiento particular de los espíritus, a modo de tuberías en el cerebro, que se fortalecerán las impresiones que sirven al sujeto.

35 representar el valor estimado de la cosa, que inclinación es causada por un movimiento especial de los espíritus.

36 Así, estas dos pasiones no son única especie de admiración. Porque cuando no amamos la grandeza ni la pequeñez de un objeto, nosotros en razón ni más ni menos estado que la razón dicta que debemos hacer; de razón que estimemos o menospreciemos entonces sin pasión.

37 Ahora estas dos pasiones se pueden generalmente referirse a todo tipo de objetos; pero son principalmente notables cuando los reportamos a nosotros mismos, es decir, cuando es nuestro propio mérito por el que nos estimamos o menospreciamos 
nous puissions avec raison estre louëz ou blasmez; \&. il nous rend en quelque façon semblables à Dieu, en nous faisant maistres de nous mesmes (A.T., XI, p. 445; 13-22) $)^{38}$.

Así las cosas, el binomio estima-menosprecio juega un papel determinante en la noción de generosidad, pues solo estimándose puede el ser humano ser generoso.

Ahora bien, para estimarse la persona debe tener presente que se posee un libre arbitrio que debe usarse bien siempre y disponer de la firme resolución de tener la voluntad fuerte y constante de hacer siempre lo que se juzga mejor. El control que tengamos sobre nuestras voliciones y el buen uso del libre arbitrio, con todo lo que ello implica (resolución firme y voluntad controlada), nos libera de la tiranía de las pasiones y nos hace dueños de nosotros mismos. Por otro lado, reaparecen los términos resolución firme y voluntad como fundamentales en la noción de generosidad. De esta manera, en el artículo CCIII, Descartes explicó que la generosidad es el remedio contra los excesos:

Pource que, faisant qu'on estime fort peu tous les biens qui peuvent estre ostez, \& qu'au contraire on estime beaucoup la liberté, \& l'empire absolu sur soy mesme, qu'on cesse d'avoir lors qu'on peut estre offensé par quelcun, elle fait qu'on n'a que du mespris, ou tout au plus de l'indignation, pour les injures dont les autres ont coutume de s'offenser (A.T., XI, p. 481; 20-26) ${ }^{39}$.

Según Descartes, utilizar bien el libre arbitrio mediante la resolución firme y la voluntad controlada hace que un hombre: «S'estime au plus haut

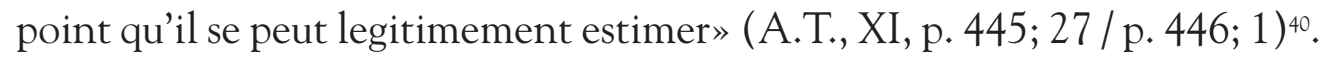
Ejercer el libre arbitrio guiado por una voluntad controlada y una resolución firme parece separar a los individuos en dos grupos: los que son libres

38 La única observación en nosotros, que una sola cosa nos puede dar una justa razón estimarnos a nosotros mismos, a saber, el uso de nuestro libre albedrío, y el imperio que tenemos en nuestra voluntad. Porque no es que sólo las acciones que dependen de este libre albedrío, por lo que puede con razón ser alabado o blasfemado; Y. nos hace de alguna manera como Dios, haciéndonos dueños de nosotros mismos.

39 por eso, se estima poco todos los bienes que pueden ser suficientes, y por el contrario se estima mucho la libertad, y el poder absoluto sobre sí mismo se deja de tener cuando se puede ser ofendido por alguien, que no tiene nada más que desprecio y que, a lo sumo indignación por las injurias que a otros suelen ofender.

40 Se siente en el punto más alto que puede legítimamente considerar. 
y pueden legítimamente estimarse por sus virtudes y los que no son libres y no pueden legítimamente estimarse por sus vicios.

Es importante indicar que el tema de la generosidad no se encuentra solo en Les passions de l'âme, también se encuentran referencias sobre la generosidad en dos cartas dirigidas a la princesa Isabel (la del 3 de noviembre de 1645 y la del 9 de octubre de 1649). En la primera Descartes expresó:

C'est toutefois vne vertu si louable de iuger fauorablement des autres, \& elle s'accorde si bien auec la generosité qui vous empesche de vouloir mesurer la portée de l'esprit humain par l'exemple du commun des hommes, que ie ne puis manquer d'estimer extrêmement I' vne \& l'autre (A.T., IV, p. 331; 2-8) ${ }^{41}$.

En la carta del 9 de octubre de 1649, desde Estocolmo, Descartes le comentó a la princesa Isabel respecto a la reina Cristina de Suecia que «la générosité et la majesté qui brillent dans toutes leurs actions» (A.T., V, p. $429 ; 10-16)^{42}$, y le indicó que su virtud y su bondad, superiores a lo que la fama le atribuye, obligan a los que están cerca a ponerse a su servicio.

Asimismo, es muy importante detenerse en la afirmación hecha por Descartes en la misiva dirigida a la princesa Isabel el 3 de noviembre de 1645:

Puisse assez estre vérifiée par l'expérience, c'est toutefois vne vertu si louable de iuger fauorablement des autres, \& elle s'accorde si bien auec la generosité qui vous empesche de vouloir mesurer la portée de l'esprit humain par l'exemple du commun des hommes, que ie ne puis manquer d'estimer extrêmement I' vne \& l'autre. c'est toutefois vne vertu si louable de iuger fauorablement des autres, \& elle s'accorde si bien auec la generosité qui vous empesche de vouloir mesurer la portée de l'esprit humain par l'exemple du commun des hommes, que ie ne puis manquer d'estimer extrêmement I' vne \& l'autre. c'est toutefois vne vertu si louable de iuger fauorablement des autres, \& elle s'accorde si bien auec la generosité qui vous empesche de vouloir mesurer la portée de l'esprit humain par l'exemple du commun des

41 sin embargo, es una virtud loable de juzgar a los demás favorablemente, y encaja muy bien con la generosidad que impide que desee medir el alcance de la mente humana por el ejemplo del común de los hombres, que no puedo yo altamente estimar lo uno y lo otro.

42 La generosidad y la majestad que brillan en todas sus acciones. 
hommes, que ie ne puis manquer d'estimer extrêmement I' vne \& l'autre (A.T., IV, p. 331; 2-8) ${ }^{43}$.

Como se puede leer, el vulgo no se puede considerar generoso, por lo menos en términos generales. Lo anterior indica cierta exclusión, por lo menos en cuanto a facultades innatas. Al parecer, la virtud de la generosidad no es común entre los seres humanos. De hecho, Descartes expresó en Les passions de l'ame que la generosidad es «a laquelle il femble que la bonne naissance contribue tant» (A.T., XI, p. 453; 18-19) ${ }^{44}$. Empero, esta aseveración no significa que estas familias a las que se refiere el genio francés pertenezcan a algún tipo de clase dominante. Lo que el filósofo de Touraine intentó comunicar es que la tendencia a la generosidad (y, por qué no, su aprendizaje en el seno de la familia) se da más en ciertos grupos familiares que en otros, sea cual sea su condición social o económica.

En el ya citado artículo CLXI se muestra cómo esta división no implica discriminación:

Qu'à celle qui fait qu'on ne s'estime que selon sa juste valeur; \& qu'il soit aysé à croyre, que toutes les âmes que Dieu met en nos corps, ne sont pas également nobles \&. fortes (ce qui est cause que j'ay nommé cette vertu Generofité, suivant l'usage de nostre langue, plutost que Magnanimité, suivant l'usage de l'Escole, où elle n'est pas fort connuë): il est certain neantmoins que la bonne institution sert beaucoup, pour corriger les défauts de la naissance (A.T., XI, p. 453, 19-27) . $^{45}$

43 Puede bastante ser verificada por la experiencia, sin embargo, es una virtud loable de juzgar a los demás favorablemente, y encaja muy bien con la generosidad que impide que desea medir el alcance de la mente humana con el ejemplo el hombre común, que no puedo dejar de estimar lo extremadamente uno y lo otro. esto es sin embargo, tal virtud loable de juzgar a los demás favorablemente, y encaja muy bien con la generosidad que impide que desea medir el alcance de la mente humana por el ejemplo del hombre común, que no puedo dejar de yo estimo altamente uno y lo otro. Sin embargo, es una virtud loable de juzgar a los demás favorablemente, y que encaja muy bien con la generosidad que impide que desea medir el alcance de la mente humana con el ejemplo del hombre común, no puedo yo altamente estimado perdir uno y otro

44 .... la que parece que el buen nacimiento contribuye tanto.

45 único que hace que no tiene en cuenta que de acuerdo a su valor razonable; es fácil creer que todas las almas que Dios pone en nuestros cuerpos no son igualmente nobles y fuertes (esto se debe a que me han llamado esta virtud la generosidad, según la costumbre de nuestro lenguaje bien tener esa magnanimidad como de costumbre en la escuela, donde no es muy bien conocido) es cierto, sin embargo, que la institución es de mucho bien para corregir defectos de nacimiento 
Para Descartes la generosidad no es una virtud exclusiva de ciertos tipos de personas según su cuna. Es verdad que algunas personas pueden nacer con ciertas ventajas. No obstante, la educación tiene el poder de corregir «pour corriger les défauts de la naissance» (A.T., XI, p. 453, 19-27) ${ }^{46}$. Entonces, más que con una cuestión de nacimiento, el acceso a la generosidad para los individuos tiene que ver con una voluntad fuerte y firme (controlada) dispuesta (tal como se ha dicho anteriormente) a utilizar el libre arbitrio y a mantener la resolución de usarlo bien, para que así cualquier individuo pueda tenerse a sí mismo, legítimamente, en la más alta estima.

Además de todo lo dicho, es importante hacer énfasis en otro concepto relacionado con la generosidad: la humildad virtuosa. Al respecto, en el artículo CLV, Descartes señaló lo siguiente:

Ainsi les plus généreux ont coustume d'estre les plus humbles; \& l'humilité vertueuse ne consiste qu'en ce que la reflexion que nous faisons sur l'infirmité de nostre nature, $\&$ sur les fautes que nous pouvons autrefois avoir commises, ou sommes capables de commetre, qui ne sont pas moindres que celles qui peuvent estre commises par d'autres, est cause que nous ne nous preferons à personne, \& que nous pensons que, les autres ayant leur libre arbitre aussi bien que nous, ils en peuvent aussi bien user (A.T., XI, p. 447; 8-17) ${ }^{47}$.

Empero, cuando el libre arbitrio se utiliza mal y la persona se estima indebidamente, es decir, se estima por las razones equivocadas siempre produce un «orgueil très blafmable, \& qui est si different de cette vraye Generosité, qu'il a des effets entierement contraires» ${ }^{48}$ (A.T., XI, p. 449; 17-19). Este conjunto de emociones, o pasiones para usar el concepto cartesiano, surge de no estimarse correctamente; en el artículo CLIX ha sido denominado por el filósofo francés como humildad viciosa, la cual

46 ...para corregir defectos de nacimiento.

47 Así, el más generoso traje tiene que ser el más humilde; y la humildad virtuosa consiste solamente en la reflexión que hacemos sobre la debilidad del nuestra la naturaleza, y en los errores que pueden tener una vez cometidos, o son capaces de cometer, que no son menos que los pueden ser cometidos por otros, es causa que nosotros no prefiramos una persona, y que nuestros pensamientos que los otros que tienen su libre albedrío, así como nosotros, ellos pueden también bien usarlo

48 ...orgullo muy censurable, y que es tan diferente de esta verdadera generosidad, que tiene efectos completamente contrarios. 
Est directement opposée à la Generosité ; \&. il arrive souvent que ceux qui ont l' esprit le plus bas, sont les plus arrogans \& superbes, en mesme façon que les plus généreux sont les plus modestes $\&$ les plus humbles. Mais au lieu que ceux qui ont l'esprit fort $\&$ généreux, ne changent point d'humeur pour les prosperitez ou adversitez qui leur arrivent, ceux qui l'ont foible $\&$ abjet, ne sont conduits que par la fortune; \& la prosperité ne les enfle pas moins, que l' adversité les rend humbles. Mesme on void souvent qu'ils s'a baissent honteusement, auprès de ceux dont ils attendent quelque profit ou craignent quelque mal; \& qu'au mesme temps ils s'elevent insolemment, au dessus de ceux desquels ils n'esperent ny ne craignent aucune chose (A.T., XI, p. 450; 10-25) $)^{49}$.

El control de nuestras pasiones nos vuelve virtuosos, nos hace dueños de nosotros mismos y nos permite ayudar a otros. En el artículo CLXXXVII Descartes expresó sobre la piedad:

Mais neantmoins ceux qui sont les plus genereux, \& qui ont l'esprit le plus fort, en sorte qu'ils ne craignent aucun mal pour eux, $\&$ se tienent au dela du pouvoir de la fortune, ne sont pas exemts de Compassion, lors qu'ils voyent l'infirmité des autres hommes, \& qu'ils entendent leurs plaintes. Car c'est une partie de la Generosité, que d'avoir de la bonne volonté pour un chacun. Mais la Tristesse de cette Pitié n'est pas amere, \& comme celle que causent les actions funestes qu'on voit representer fur un theatre, elle est plus dans l'extérieur \& dans le sens, que dans l'intérieur de lame, la quelle a cependant la satisfaction de penser, qu'elle fait ce qui est de son devoir, en ce qu'elle compatit avec des affligez. Et il y a en cela de la différence, qu'au lieu que le vulgaire a compassion de ceux qui se plaignent, à cause qu'il pense que les maux qu'ils souffrent font fort fascheux, le principal objet de la Pitié des plus grands hommes est la foiblesse de ceux qu'ils voyent se plaindre: à cause qu'ils n'estimeni point qu'aucun accident qui puisse arriver, soit un si grand mal, qu'est la Lascheté de ceux qui ne le peuvent soufifrir avec constance.

49 Es directamente opuesto a la generosidad; y sucede a menudo que aquellos que tienen el espíritu más bajo, son los más arrogantes y soberbios en la misma manera que los más generosos son los más modestos y los más humildes. Pero en lugar de aquellos de espíritu fuerte y generoso, que no cambian de humor por la prosperidad o las adversidades que a ellos les suceda, aquellos que lo tienen débil y abyecto, son impulsados únicamente por la fortuna; y la prosperidad no les hincha menos, que la adversidad les hace humildes. Igual es al vacío que a menudo caen vergonzosamente, aquellos que esperan algún beneficio o temen algún mal; y que al mismo tiempo se elevan insolentemente por encima de los que no esperan ni temen cosa alguna. 
Et bien qu'ils haïssent les vices, ils ne haïssent point pour cela ceux qu'ils y voyent sujets : ils ont seulement pour eux de la Pitié (A.T., XI, p. 469; $22-23 /$ p. $470 ; 1-23)^{50}$.

La buena voluntad del generoso se extiende a todas las demás personas. La persona generosa es compasiva ante las debilidades de los otros. Escuchar con paciencia las quejas de sus semejantes, por quienes siente una gran compasión que no es amarga, crea en el generoso un sentimiento de apoyo y respaldo por las debilidades de los demás. La persona generosa no solo se controla, también es tolerante y solícita con las otras personas de espíritus débiles que aún son esclavas de los vaivenes de la fortuna. El individuo generoso apoya y (¿guía?) al individuo de espíritu débil.

Descartes mostró la generosidad como la virtud por excelencia, la cual se desarrolla con el correcto ejercicio del libre arbitrio, que a su vez se consigue mediante el control de la voluntad. No obstante, en ocasiones la voluntad no basta: «Si ce n'est pour être appliquée en considérant les motifs, les objets ou les exemples qui ont convaincu que le danger n'est pas très grande» (A.T., XI, p. 363; 3-5 51. Un ser humano generoso lo es porque primero controla su voluntad y sus pasiones, según el dictado de la razón.

\section{La beatitud y la razón}

Para iniciar este apartado es necesario saber que la beatitud en Descartes o, mejor dicho, el vivere beate es, a grandes rasgos, el equivalente de vivent heureux en francés, siendo esta comparación lo más cercano a una definición clara y distinta al respecto. No obstante, esta noción es ampliada

50 Sin embargo, aquellos que son los más generosos, y que tienen el espíritu más fuerte, que no temen ningún mal para ellos, y están más allá de la tentación del poder de la riqueza, no están exentos de la compasión cuando ven la debilidad de otros hombres, y que escuchan sus quejas. Porque es parte de la generosidad, que tener la buena voluntad por cada uno. Pero la tristeza de esta misericordia no es amargo, y como el que causa la acción fatal que como un teatro, es más en el exterior y en el sentido de que en el interior del alma, que sin embargo tiene la satisfacción de pensar, que hace lo que es su deber, ya que simpatiza con el duelo. Y no está en la diferencia de que en lugar de la vulgar compasión los que se quejan, a causa de que piensa que los males que sufren son desafortunadamente fuertes, el objeto principal de la piedad más grandes hombres es la debilidad de los que veían quejarse: porque estiman elemento accidental que puede suceder, un gran mal, que es la cobardía de los que sí puede someterse con consistencia. Y a pesar de que odian a los vicios, odian este punto para aquellos que son sujetos que ven: sólo para ellos la misericordia.

51 Si no es para ser aplicado en el examen de los motivos, los objetos o ejemplos que han convencido el peligro no es genial. 
y explicada en varios momentos distintos. En la carta del 18 de agosto de 1645, dirigida a la princesa Isabel, Descartes expresó que:

Au lieu que la béatitude consiste, ce me semble, en vn parfait contentement d'esprit \& vne satisfaction intérieure, que n'ont pas ordinairement ceux qui sont le plus fauorisez de la fortune, $\&$ que les sages acquerent sans elle. Ainsy viuere beate, viure en beatitude, ce n'est autre chose quauoir l'esprit parfaitement content \& satisfait (A.T., IV, p. 264; 7-13) $)^{52}$.

En la misiva del 18 de mayo de 1645 a la princesa Isabel el filósofo de Touraine expresó: «\& l'opiniastreté de la Fortune à perfecuter vostre maison, vous donne continuellement des suiets jo de fascherie» (A.T., IV, p. 201; 18-19) $)^{53}$

Luego indicó: «Du tout déliurée, si ce n'est que, par la force de j vostre vertu, vous rendiez vostre ame contente, malgré les disgraces de la Fortune» (A.T., IV, p. 201; 25-27) 54. Y más adelante agregó: «Se considerant comme immortelles $\&$ capables de receuoir de très-grands contentemens» (A.T., IV, p. 202; 19-20 $)^{55}$.

Ese mismo año, el 1 de setiembre, el filósofo francés le escribió a la princesa Isabel que la beatitud es el contento máximo y que existen bienes que nos brindan felicidad, pero no cualquier bien. Los bienes que nos darán contento son los que conseguimos según el buen uso de la razón, según la cual: "Car toutes les actions de nostre ame qui nous acquerent quelque perfection, sont vertueuses, $\&$ toutnostre contentement ne consiste qu'au tesmoignage intérieur que nous auons d'auoir quelque perfection» (A.T., IV, p. 283; 27-29/ p. 284; 2) $)^{56}$.

Entonces, según la carta a la princesa Isabel (1 de septiembre de 1645), «la béatitude qui depend entièrement de nostre libre arbitre \& que tous les

52 En lugar de bienaventuranza es, creo yo, es una perfecta satisfacción de espíritu y una satisfacción interior que no lo tienen por lo general los que están la más favorecidos de la fortuna, y que los sabios adquieren sin ella. Así viven beatos, viven en la beatitud, esto no es otra cosa que tener el espíritu perfectamente contento y satisfecho.

53 Y la obstinación de la Fortuna de perpetrar vuestra casa, continuamente hace de los sujetos su fastidio.

54 Toda emitida, si no es que por la fuerza de vuestra virtud, dirigen vuestra alma feliz a pesar de las desgracias de la fortuna.

55 Se consideran como inmortales y capaces de recibir los más grandes contentos.

56 ...porque cada acción de nuestra alma que nos adquieren alguna perfección, son virtuosas, y todo nuestro contento solo es testimonio interno que tenemos alguna perfección 
hommes peuuent acquérir sans aucune assistance d'ailleurs» (A.T., IV, p. $281 ; 19-22)^{57}$, es decir, que la beatitud está al alcance de todos, solo hay que sentirse contento con uno mismo por las razones correctas, es decir, por el ejercicio de las virtudes verdaderas.

En la carta del 6 de octubre Descartes le hablaba a la princesa Isabel sobre la beatitud:

Toutefois, comme vn pettit, vaisseau peut estre aussy plein qu vn plus grand, encore qu il contiene moins de liqueur, ainfy, prenant le contentement d vn chaseun pour la plenitude y l' accomplissement de ses desirs reglez selon la raison, ie ne doute point que les point que les plus pauures y les plus disgraciez de la fortune ou de la nature ne puissent estre entierement contens y satisfaits, aussy bien que les autres, encore qu ils ne iouissent pas de tant de biens (A.T., IV, p. 264; 25-30/ p. 265; 1-3) . $^{58}$.

Más adelante le decía: «Pour cela de la béatitude dont il est question, pour ce qu'elle doit dépendre de nostre conduite, \& cela ne viendroit que

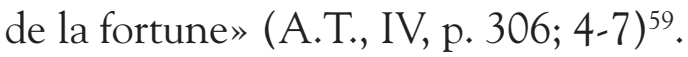

De acuerdo con lo anterior, no hay duda de que para Descartes cualquier persona puede acceder al contento y a la satisfacción, indistintamente de su cuna o su situación económica. Lo que es verdaderamente determinante para alcanzar el contento es regular los deseos según la razón. Una persona puede ser noble por nacimiento y a la vez un desdichado, si su espíritu, lejos de encontrarse en equilibrio y paz, se mueve al ritmo de los altibajos de la fortuna.

Descartes distinguió entre lo que se pueden llamar almas comunes o del vulgo y las almas nobles o generosas, estas últimas están por encima de las «bien qu'elles ayent aussi des passions, $-\&$ mesme souuent de plus violentes que celles du commun, leur raison demeure neantmoins tousiours la

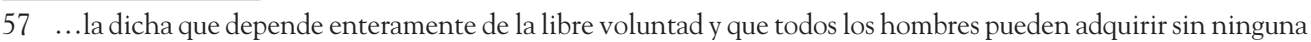
ayuda en otros lugares...

58 Sin embargo, como un vaso pequeño puede estar tan lleno que uno más grande, empero, contiene mucho menos licor que él y tomando la alegría de una plenitud que hay en cada uno para el cumplimiento de sus deseos conjunto a la razón, es decir, sin duda, señalar el punto en el que los más pobres son los más desgraciados de la fortuna o de la naturaleza no puede ser del todo satisfecho contento allí, también así como otros, que todavía no gozan de tanto bien [...].

59 Para que la bienaventuranza que está en cuestión, porque ella depende de nuestro comportamiento, y esto no viene de la fortuna 
maistresse, \& fait que les afflictions mesme leur seruent, \& contribuent à laparfaite félicité dont elles iouïssent dés cette vie» (A.T., IV, p. 202; 13-18)60.

En una carta posterior el filósofo francés le reiteró esta idea a la princesa Isabel diciéndole que solo disponía de un tema para compartir y es «que de parler des moyens que la Philosophie nous enseigne pour acquérir cete souueraine félicité, que les âmes vulgaires attendent en vain de la fortune, \& que nous ne sçaurions auoir que de nous mesmes» (A.T., IV, p. 252; 15-19) ${ }^{61}$.

A modo de resumen, respecto al tema de la beatitud diré, igual que Descartes, que puede «icy conclure que la béatitude ne consiste qu'au contentement de l'esprit, c'est a dire au contentement en general» (A.T., IV, p. $277 ; 15-17)^{62}$. La beatitud para Descartes es la felicidad, la alegría de un espíritu que se estima legítimamente, pues controla su voluntad de acuerdo con su razón.

\section{La sabiduría}

Cuando las virtudes «sont tellement pures et parfaites qui non seulement viennent mais la connaissance du bien sont tous de même nature, et peut être compris sous le seul nom de la sagesse» (A.T., IX, p. 2; 22) ${ }^{63}$.

Aquí Descartes señaló que la sabiduría se alcanza cuando se consiguen la perfección y la pureza de las virtudes. Por otra parte, según la epístola dedicatoria a la princesa Isabel, la virtud, para ser tal, debe provenir de la sabiduría. La carta dedicatoria continúa:

Car quiconque a vne volonté ferme \& confiante d'vfer touf-jours de la raison le mieux qu'il est en son pouuoir, \& de faire en toutes ses adions ce qu'il juge estre le meilleur, est véritablement sage, autant que sa nature permet qu'il le soit; \& par cela seul il est juste, courageux, modéré, \& a toutes les autres

60 ...bien que ellas tengan también pasiones y a menudo violentas que las del resto/común, su razón persiste, sin embargo es siempre el dominio, y ella hace de las aflicciones convenientes y ellas contribuyen a la felicidad perfecta de la cual gozan en esta vida.

61 ...que hablar de las palabras que la filosofía nos enseña para adquirir esta soberana felicidad que las almas vulgares esperan en vano de la fortuna, y que nosotros no sabemos que tenemos de nosotros mismos.

62 ....quí la conclusión de que la bienaventuranza no consiste en alegría de la mente, es decir, en la alegría general.

63 ...son tan puros y perfectos que no sólo vienen pero el conocimiento del bien son todos de la misma naturaleza, y puede ser entendida bajo el nombre de sabiduría. 
vertus, mais tellement jointes entre elles qu'il n'y en a aucune qui paroiffe plus que les autres (A.T., IX, p. 2; 22) 64. $^{6}$.

El virtuoso es sabio y el sabio es virtuoso. No obstante, el vínculo que los une es una voluntad firme, controlada. Sin una voluntad controlada por la razón no se podrá juzgar acertadamente. Entonces, el sabio es una persona que controla su voluntad mediante la razón y no por otros medios: «Compréhension qui sait tout ce qui est bon et que la volonté est toujours prêt à suivr» (A.T., IX, p. 2; 22$)^{65}$.

El control de la voluntad o la resolución firme es tan importante para Descartes que incluso aquellas personas con pocos conocimientos pueden acceder a la virtud: «Si seulement ils ont touf-jours vne ferme resolution de faire tout le bien qu'ils sçauront, $\&$ de n'ometre rien pour apprendre celuy qu'ils ignorent» (A.T., IX, p. 2; 22) ${ }^{66}$.

Para Descartes la sabiduría no es una cuestión exclusiva de ciertos espíritus. Es verdad que algunas personas nacen con espíritus predispuestos a la sabiduría, empero: «Toutefois, ceux qui ont un désir constant de faire le bien et très particulier soin de se renseigner, ont aussi un très bon esprit, certainement atteindre un degré de sagesse supérieure que les autres» (A.T., IV, p. 245;22) ${ }^{67}$.

En la misiva a la reina Cristina de Suecia del 20 de noviembre de 1647 Descartes señaló que:

La vertu ne consiste qu'en la resolution \& la virgueur auec laquelle on se porte à faire les choses qu'on croit estre bonnes, pouruû que cette vigueur ne vienne pas d'opiniastreté, mais de ce qu'on scait les auoir autant examinées, qu'on en a moralement de pouuoir que cette vigueur ne vienne pas d'opiniastreté (A.T., V, p. 83; 27 / p. 84; 1) ${ }^{68}$.

64 Porque cualquiera con una voluntad firme y confiada de hacer todos los días de la razón lo mejor que está en su poder, y de hacer sus acciones las que él juzgue ser la mejor, es verdaderamente sabio, en cuanto a su naturaleza permite que sea; y porque solo él es justo, valiente, moderado, y tiene todas las otras virtudes, más así unido entre ellas que no hay ninguno que disfrute más que los otros

65 Comprensión que sabe todo lo que es bueno y que la voluntad está siempre dispuesto a seguir...

66 Si sólo ellos siempre tienen la firme resolución de hacer todo el bien que saben y de no cometer nada por aprender lo que ellos ignoran.

67 Sin embargo, aquellos que tienen un deseo constante de hacer el bien y más particular cuidar de aprender, también tienen un muy buen espíritu, sin duda alcanzar un grado de sabiduría superior que otros.

68 La virtud no consiste sólo en la resolución y el vigor con que una puerta para hacer las cosas que creemos que es bueno, por lo que esta fuerza no proviene de la obstinación 


\section{La sabiduría y la filosofía}

En la carta-prefacio Descartes dice que la filosofía es el estudio de la sabiduría, y que la Sabiduría es o consiste no solo en la prudencia en las labores, sino también en un perfecto entendimiento ${ }^{69}$ de todas las cosas que el ser humano puede saber, y este saber implica la conducción de su vida, la conservación de la salud y la producción de todas las artes (A.T., IX-2, 2, 5-13). Empero, para que este conocimiento sea verdadero la persona tiene que desprenderlo de las causas primeras, es decir, debemos «commencer par la recherche de ces premières causes, c'est à dire des Principes» (A.T., IX-2; 300; 17-18) ${ }^{70}$.

Las causas primeras a las que se refirió el filósofo francés, para ser tales, deben cumplir dos requisitos: uno, que «est-ce si clair et évident que l'esprit humain ne peut pas douter de sa vérité et, deux, cela dépend d'eux la connaissance d'autres choses» (A.T., IX-2; 300; 20-25) ${ }^{71}$. Después de garantizar que estos principios son verdaderos, se puede derivar conocimiento de ellos.

Para que el conocimiento sea verdadero debe presentar fundamentos últimos, estos soportan los conocimientos del mismo modo en el que los fundamentos soportan un edificio. En el caso de Descartes, su fundamentalismo entiende la relación entre los fundamentos y lo fundado por ellos, el modo en el que los conocimientos derivan de los fundamentos.

Además, hay varios modos de entender los fundamentos. El modo clásico, del que se tiene un ejemplo en Descartes, consiste en admitir como absolutamente cierta, indudable y evidente por sí misma una proposición (Ferrater, 1963).

En la carta-prefacio Descartes presentó también una suerte de niveles de conocimiento que se deben alcanzar antes de llegar al conocimiento parfait, y según él: «Toute la Sageffe qu'on a couflume d'auoir n'efl acquife que par ces quatre moyens» (A.T., IX, p. 1; 13-15) ${ }^{72}$.

Estos cinco niveles son: el conocimiento que abraza nociones tan claras que se pueden adquirir sin meditación; el que comprende todo lo que

\footnotetext{
69 Entendimiento no se utiliza aquí en relación de sinonimia con el concepto de razón, sino como el proceso mental por medio del que nuestro cerebro interpreta la información que nos proporcionan nuestros sentidos.

70 ...comenzar por la búsqueda de estas primeras causas, es decir los principios.

71 ...es tan claro y evidente que la mente humana no puede dudar de su verdad y, dos, que depende del conocimiento de otras cosas...

72 Toda la sabiduría que han adquirido en la práctica por estas cuatro formas
} 
la experiencia admite conocer; el conocimiento que se adquiere mediante la conversación con otros hombres; el que proviene de la lectura de libros que nos dan instrucciones provechosas; y el quinto grado de sabiduría es:

Incomparablement plus élevé et plus sûr que les quatre autres : la première consiste à rechercher les véritables causes et les principes qui sont des raisons plausibles de tout ce que l'on est capable de savoir, et les hommes qui ont travaillé surtout dans ce qu'ils Les philosophes appelés (A.T., IX, p. 5; 3-27)73.

No obstante, el mismo Descartes afirmó no conocer, hasta ese momento, a nadie que hubiera alcanzado el quinto nivel (A.T., IX, p. 5; 3-27). Es muy interesante que Descartes denominara a los filósofos como chercheurs de sabiduría, aquellos que se han esforzado por alcanzar el quinto nivel de sabiduría, pero «cela ne pouvait pas venir à la connaissance des vrais principes» (A.T., IX-2, 8, 16-23; 7, 18-20, 28-29)74. Es decir, los filósofos serían los que más se han acercado a la sabiduría con todo lo que ello implica, no solo en el nivel propiamente cognitivo, sino también en lo que concierne a la conducción de la vida, la cual, si es correcta, debe basarse en una voluntad suficientemente fuerte para controlarse a sí misma.

En cuanto a la concepción de sabiduría, la carta-prefacio y la epístola dedicatoria, prólogos de los Principia Philosophiae, muestran concepciones complementarias. La carta-prefacio posee un sentido del conocimiento científico y metafísico que la epístola no tiene. Empero, la epístola dedicatoria contiene conocimiento de tipo moral. Ambas concepciones nos acercan a la noción de sabiduría de Descartes, una sabiduría que depende tanto del conocimiento como del ejercicio de la virtud, respaldada por una voluntad firme, controlada y dirigida siempre por la razón.

\section{El soberano bien}

Según Descartes el soberano bien es «la bonté de chaque chose en elle-mesme, sans la rapporter à autruy, auquel sens il est euident que c'est

\footnotetext{
73 Incomparablemente mayor y más seguro que los otros cuatro: el primero consiste en la búsqueda de las verdaderas causas y principios que son razones plausibles para todo lo que uno es capaz de conocer, y los hombres que trabajaban principalmente a quienes llaman filósofos.

74 ...no podía llegar al conocimiento de los principios verdaderos.
} 
Dieu qui est le fouuerain bien, pource qu'il est incomparablement plus parfait que les créatures» (A.T., V, p. 82; 7-11) 75.

Descartes también creía que el soberano bien «ne consiste qu'en vne ferme volontè de bien faire, $\&$ au contentement qu'elle produit» (A.T., V, p. $82 ; 29-31)^{76}$. Ahora:

C'est pourquoy il ne neste que nostre voluntè, dont nous puissions absolument disposer. Et ie ne voy point qu'il soit possible d'en disposer mieux, que si l'on a tousiours vne ferme $\&$ constante resolution de faire exactement toutes les choses que l'on iugera estre les meilleures, \& d'employer toutes les forces de son esprit à les bien connoistre. C'est en cela seul que consistent toutes les vertus; c'est cela feul qui, à proprement parler, merite de la loüange \& gloire ; enfin c'est de cela seul que resulte tousiours le plus grand $\&$ le plus solide contentement de la vie (A.T., V, p. 83; 7-18) ${ }^{77}$.

Más adelante, en la misma carta, el filósofo francés expresó que solo en esto consisten las virtudes: «Ainsi i'estime que c'est en cela que consiste le souuerain bien» (A.T., V, p. 83; 18-19) ${ }^{78}$.

En la epístola anterior (6 de octubre de 1645) Descartes ya había apuntado que

Mais ie distingue entre le souuerain bien, qui consiste en l'exercice de la vertu, ou ce qui est le mesme, en la possession de tous les biens dont l'acquisition depend de nostre libre arbitre, \& la satistaction d'esprit qui suit de cette acquisition (A.T., IV, p. 305; 6-15) ${ }^{79}$.

75 ...la bondad de cada cosa en sí misma, sin relación con otro, en el que sentir que es obvio que es Dios quien es el soberano bien, porque es incomparablemente más perfecto que las criaturas...

76 ...consiste sólo en una firme voluntad de hacer bien, y el contento que ella produce...

77 Es porque nuestra voluntad es lo único que absolutamente podemos tener. Y yo no voy punto de que es posible disponer de una mejor, si uno tiene cualquier constante resolución firme y séptimo día de hacer precisamente todo lo que consideramos que es el mejor, y emplear todos obliga a la mente a la conocer también. Es sólo que involucran todas las virtudes que sólo hay una que, en rigor, merece la alabanza y la gloria finalmente es esto solo que convierte cada día el más grande y más fuerte la alegría de la vida.

78 Y yo creo que es en esto en lo que consiste el bien supremo.

79 Es porque nuestra voluntad es lo único que absolutamente podemos tener. Y yo no voy punto de que es posible disponer de una mejor, si uno tiene cualquier constante resolución firme y séptimo día de hacer precisamente todo lo que consideramos que es el mejor, y emplear todos obliga a la mente a la conocer también. Es sólo que involucran todas las virtudes que sólo hay una que, en rigor, merece la alabanza y la gloria finalmente es esto solo que convierte cada día el más grande y más fuerte la alegría de la vida. 
A lo largo de este trabajo he mostrado, mediante citas de la correspondencia de Descartes con diversos destinatarios y varias de sus obras publicadas, la influencia del estoicismo, de Aristóteles y Epicuro en el filósofo de Touraine y cómo se desarrollan en el pensamiento de Descartes, quien consideró a quienes controlan sus pasiones adecuadamente, es decir escuchando a la razón, como espíritus nobles, y a quienes no controlan sus pasiones como espíritus débiles.

Aquellos espíritus que entristecen hasta lo más hondo o sufren la más alta euforia, según sean los acontecimientos, no son libres. No son ni dejarán de ser esclavos mientras sus pasiones se muevan al compás de los vaivenes de las circunstancias. Nunca serán dueños de sí mismos si no controlan sus pasiones.

Los espíritus virtuosos que se mantienen temperados (también llamados nobles) ante las situaciones de la vida, sean convenientes o inconvenientes, son libres. El hábito, la meditación y el buen uso del libre arbitrio los vuelve dueños de sí mismos en cuanto sus pasiones les obedecen y no al revés. Son felices, puesto que su dicha no está dictada por nada externo a ellos, y pueden con toda legitimidad llamarse a sí mismos generosos, es decir, poseedores de la más alta virtud.

La persona generosa no lo es solo por estimarse a sí misma legítimamente, o sea, por controlar su voluntad y con ella sus pasiones, lo es por ser agradecida, porque es paciente con las flaquezas de los espíritus débiles y porque los apoya en sus momentos de tristeza.

La persona virtuosa es alguien que no solo piensa en sí misma, sino también en los demás y está dispuesta a ayudarlos a mejorar, a controlar su voluntad y a que con el tiempo puedan tal vez caminar los senderos que llevan a la verdad. 


\section{Bibliografía}

Adam, C y Tannery, P. (1996). OEuvres de Descartes. Paris: Libraire philosophique J. Vrin. Tomos I- XI.

Cajigas-Rotundo, J. (2007). "La biocolonialidad del poder. Amazonía, biodiversidad y ecocapitalismo". En Santiago Castro-Gómez y Ramón Grosfoguel (comps.). El giro decolonial. Reflexiones para una diversidad epistémica más allá del capitalismo global. Bogotá: Universidad Javeriana-Instituto Pensar, Universidad Central-IESCO, Siglo del Hombre Editores.

Castro-Gómez, S. (2005). La hybris del punto cero. Ciencia, raza e Ilustración en la Nueva Granada 1750-1816. Bogotá: Universidad Javeriana-Instituto Pensar.

Castro-Gómez, S. (1996). Crítica de la razón latinoamericana. Barcelona: Puvill Libros.

Castro-Gómez, S. (2005). "Ciencias sociales, violencia epistémica y el problema de la 'invención del otro". En Edgardo Lander (comp.). La colonialidad del saber: eurocentrismo y ciencias sociales. Perspectivas Latinoamericanas. Buenos Aires: Clacso.

Castro-Gómez, S. (Ed.). (2000) La reestructuración de las ciencias sociales en América Latina. Bogotá: Instituto Pensar.

Castro-Gómez, S, Guardiola-Rivera, O. y Millán de Benavides, C (Eds.). (1999) Pensar (en) los intersticios. Teoría y práctica de la crítica poscolonial. Bogotá: Instituto Pensar.

Copleston, F. (1985) A history of philosophy. New York : Image Books

Davenport, A. (2002). Descartes's theory of action. Boston: Editorial Board.

Descartes, R. (1986). Discurso del método. Madrid: Alianza Editorial.

Dussel, E. (1983). Introducción a la filosofía de la liberación. Bogotá: Editorial nueva América.

Dussel, E. (1992). "Del descubrimiento al desencubrimiento". En: Nuestra América frente al V centenario. Bogotá: Editorial El Búho.

Dussel, E. (2005). "Europa, modernidad y eurocentrismo". En Edgardo Lander (comp.). La colonialidad del saber: eurocentrismo y ciencias sociales. Perspectivas Latinoamericanas. Buenos Aires: Clacso.

Dussel, E. (1992). 1492. El encubrimiento del otro. Hacia el origen del mito de la modernidad. Madrid: Nueva Utopía.

Dussel, E. (1998). Ética de la liberación en la edad de la globalización y de la exclusión. Madrid: Trotta.

Dussel, E. (2007). Política de la liberación. Historia mundial y crítica. Madrid: Trotta.

Escobar, A. (2005) Más allá del Tercer Mundo: Globalización y Diferencia. Bogotá: ICANH.

Escobar, A. (s. f.) "Mundos y conocimientos de otro modo". Recuperado de: http://www. decoloniality.net/files/escobar-tabula-rasa.pdf

Fanon, F. (2003). Los condenados de la tierra. Prefacio de Jean-Paul Sartre. Epílogo de Gérard Chaliand. México: Fondo de Cultura Económica.

Ferrater, J. (1963). Diccionario de filosofía. Barcelona: Ariel.

Foucault, M. (2000). La verdad y las formas jurídicas. Barcelona: Gedisa.

Foucault, M. (1987). Vigilar y castigar. Madrid: Alianza Editorial.

Galilei, G. (1891). El ensayador. Buenos Aires: Aguilar.

Galeano, E. (1992). Ser como ellos y otros artículos. Buenos Aires: Siglo XIX. 
Garcés, F. (2007). "Las políticas del conocimiento y la colonialidad lingüística y epistémica". En Santiago Castro-Gómez y Ramón Grosfoguel (comps.). El giro decolonial. Reflexiones para una diversidad epistémica más allá del capitalismo global. Bogotá: Universidad Javeriana-Instituto Pensar, Universidad Central-IESCO, Siglo del Hombre Editores.

Gilson, E. (1952). Jean Duns Scot. Introduction a ses positions fondamentales. París: Libraire philosophique J. Vrin.

. (1947). La philosopie au moyen age. París: Payot.

. (1966). L' index scolastico cartesien. Paris: Vrin

.(1925). R. Descartes, Discours de la méthode. Paris: Vrin

Grosfoguel, R. (2007). "Decolonizando los universalismos occidentales: el plu-riversalismo transmoderno decolonial desde Aimé Césaire hasta los Zapatistas". En Santiago Castro-Gómez y Ramón Grosfoguel (comps.). El giro decolonial. Reflexiones para una diversidad epistémica más allá del capitalismo global. Bogotá: Universidad Javeriana-Instituto Pensar, Universidad Central-IESCO, Siglo del Hombre Editores.

Habermas, J. (1986) La modernidad un proyecto incompleto. En VVAA, La posmodernidad. Barcelona: Kairós.

Jolivet, R. (1945). Las fuentes del idealismo. Buenos Aires: Ediciones Desclée, De Brouwer.

Kamen, H. (1999). La inquisición española. Una revisión histórica. Barcelona, Crítica.

Lander, E. (Ed.). (2000) La colonialidad del saber. Eurocentrismo y ciencias sociales. Perspectivas latinoamericanas. Buenos Aires: CLACSO.

Herrera, B. (2007) Las dos caras de la moneda: modernidad colonial y metropolitana. En: Pasos. San José: DEI.

Husserl, E. (1991). La crisis de la ciencias europeas y la fenomenología trascendental. Barcelona: Editorial Crítica.

Kant, I. (1996). Fundamentación para una metafísica de las costumbres. Madrid: Gredos.

Maldonado-Torres, N. (2007). "Sobre la colonialidad del ser: contribuciones al desarrollo de un concepto". En Santiago Castro-Gómez y Ramón Grosfoguel (comps.). El giro decolonial. Reflexiones para una diversidad epistémica más allá del capitalismo global. Bogotá: Universidad Javeriana-Instituto Pensar, Universidad Central-IESCO, Siglo del Hombre Editores.

Mignolo, D. W. (2005). "La colonialidad a lo largo y a lo ancho: el hemisferio occidental en el horizonte colonial de la modernidad". En Edgardo Lander (comp.). La colonialidad del saber: eurocentrismo y ciencias sociales. Perspectivas Latinoamericanas. Buenos Aires: Clacso.

Mignolo, D. W. (2002). Historias locales/ diseños globales. Colonialidad, conocimientos subalternos y pensamiento fronterizo. (Prefacio). México: Akal Ediciones.

Mignolo, D. W. (2007). "El pensamiento decolonial: desprendimiento y apertura". En Santiago Castro-Gómez y Ramón Grosfoguel (comps.). El giro decolonial. Reflexiones para una diversidad epistémica más allá del capitalismo global. Bogotá: Universidad Javeriana-Instituto Pensar, Universidad Central-IESCO, Siglo del Hombre Editores.

Mignolo, W. (Ed.). (2001) Capitalismo y geopolítica del conocimiento. El eurocentrismo y la filosofía de la liberación en el debate internacional contemporáneo. Buenos Aires: Ediciones del Signo.

Negri, A. (2008) Descartes Político. Madrid: Ediciones Akal. 
O’Gorman, E. (2002). La invención de América. México: Fondo de Cultura Económica.

Pachón, D. (2006). Filosofía vitalista y economía solidaria. Bogotá: Produmedios.

Quijano, A. (2005). "Colonialidad del poder, eurocentrismo y América Latina”. En Edgardo Lander (comp.). La colonialidad del saber: eurocentrismo y ciencias sociales. Perspectivas Latinoamericanas. Buenos Aires: Clacso.

Quijano, A. (2007). "Colonialidad del poder y clasificación social". En Santiago Castro-Gómez y Ramón Grosfoguel (comps.). El giro decolonial. Reflexiones para una diversidad epistémica más allá del capitalismo global. Bogotá: Universidad Javeriana-Instituto Pensar, Universidad Central-IESCO, Siglo del Hombre Editores.

Quijano, A. (1998) "Colonialidad, Poder, Cultura y Conocimiento en América Latina". En: Anuario Mariateguiano, vol. IX, No. 9, pp.113-122. Lima.

Quijano, A. (1992) "Colonialidad y Modernidad/Racionalidad". En: Heraclio Bonilla (comp.): Los Conquistados. 1492 y la población indígena de las Américas. Bogotá: FLACSO-Tercer Mundo.

Quijano, A. (1989) Modernidad, Identidad y Utopía en América Latina. Quito: Ediciones El Conejo.

Restrepo, E. (2007). “Antropología y colonialidad”. En Santiago Castro-Gómez y Ramón Grosfoguel (comps.). El giro decolonial. Reflexiones para una diversidad epistémica más allá del capitalismo global. Bogotá: Universidad Javeriana-Instituto Pensar, Universidad Central-IESCO, Siglo del Hombre Editores.

Sepúlveda, Juan Gines de, (1951) Demócrates segundo o de las justas causas de la guerra contra los indios. (A. Losada, Ed.). Madrid: Consejo Superior de Investigaciones científicas Instituto Francisco de Vitoria. Recuperado de: www.books.google.com/ Juan_Ginés_de_Sepúlveda

Sepúlveda, G. (1987) Tratado sobre las justas causas de la guerra contra los indios. México: Fondo de Cultura Económica.

Todorov, T. (1987) La Conquista de América. El problema del otro. México, Ed. Siglo XXI.

Walsh, C. (2007). "Interculturalidad y colonialidad del poder. Un pensamiento y posicionamiento 'otro' desde la diferencia colonial”. En Santiago Castro-Gómez y Ramón Grosfoguel (comps.). El giro decolonial. Reflexiones para una diversidad epistémica más allá del capitalismo global. Bogotá: Universidad Javeriana-Instituto Pensar, Universidad Central-IESCO, Siglo del Hombre Editores.

Weber, M. (1997). La ética protestante y el espíitu del capitalismo. Barcelona: Editorial Península. 